\title{
MODELLING DECISION-MAKING PROCESSES IN BIDDING PROCEDURES WITH THE USE OF THE FUZZY SETS THEORY
}

\author{
Edyta PLEBANKIEWICZ a,* \\ ${ }^{a}$ Institute of Building and Transport Management, Cracow University of Technology, Warszawska 24, \\ 31-155 Kraków, Poland
}

Received 26 May 2012; accepted 16 May 2013

\begin{abstract}
In the bidding procedure not only the contractor but also the construction owner make a number of vital decisions, the consequences of which are significant. The contractor has to decide whether to take part in a given bid and, having been accepted, he/she has to prepare a bidding offer. Its essential element is the mark-up introduced to the calculation of the bidding price. On the other hand, the investing construction owner has to decide which contractors are the closest to his/her requirements. The article presents mathematical models concerning the decisions made by the contractor and construction owner in the bidding procedure. All the models are based on the same simple mathematical apparatus using fuzzy sets.
\end{abstract}

KEYWORDS: Bidding procedures; Mark-up decision; Bid/no bid decision; Prequalification; Fuzzy sets theory

\section{INTRODUCTION}

A building's life cycle is usually considerably long. In order to maintain its good technical condition, numerous repair works and some modernization are necessary during this period. Various studies have revealed that tenders of construction works issued by public owners included a considerable number of orders of repair works, encompassing approximately $40 \%$ of all tenders (Plebankiewicz, Leśniak 2011).

Contractors for building works, including repair and modernization ones, are usually chosen by means of bidding. This is relevant for both public and private owners. During the bidding procedure both the contractor and the construction owner make a number of important decisions. One of the first decisions that the contractor makes is whether to take part in the bid. This decision has a significant influence on the company's situation. On the one hand, not participating in the bid deprives the contractor of the chance to take part in the building construction and, consequently, of the profits. On the other hand, the contractor has to consider whether, for instance, he/she has the

\footnotetext{
* Corresponding author. E-mail: eplebank@izwbit.pk.edu.pl
}

means to complete a given project. It is also worth noting that a contractor who has lost a number of bidding processes harms his/her reputation.

Having decided about taking part in the bid, the bidder must prepare the offer in the way the construction owner wishes it to be. One of its basic elements is the estimation of the price for which the bidder will be willing to accomplish the project. The price has to be high enough for the contractor to do the tasks properly, but at the same time lower than the price of other bidders. In stabilized economy, with high competition, contractors fight to win contracts, to a great extent, by the height of the mark-up rate they hold. Bid decisions are generally considered to be complex and difficult, and additionally they considerably influence the situation of the company. Mistakes made here may cause increasing difficulties, bankruptcy including.

On the other hand, the most important decisions made by the construction owner is the choice of the contractor who is the closest to the owner's expectations. Although the lowest price continues to be the most basic criterion for deciding about the choice of the contractor, construction owners begin to value the contractor's qualifications. Choosing the right contractor increases the chances of reach- 
ing the goals of the project which, first of all, are keeping the schedule of the cost, time and quality. The choice of competent contractors can also ensure an appropriate management of the funds allotted for the necessary repairs of buildings. The strategy of contractor selection adopted here constitutes an element of the general real estate management strategy, with the focus on the finances associated with it. The construction owner may employ various forms of contractor selection. In many countries the procedure of prequalification is commonly used as a before-tendering contractor selection method.

The decisions the construction owner has to make have a number of common features. They all require considering many factors and evaluation criteria. The decisions are normally made by a panel of decision makers, which means that there will exist many evaluations to be considered. The factors which are involved are often hard to quantify or unambiguously evaluate. The decisions are often made in short time. This makes it necessary to design a model of such decision making. Taking into account the lack of precision of many factors, it is best to use the fuzzy sets theory as the basis of the model.

The aim of the present article is to describe the author's own models for bidding decisions employing the fuzzy sets theory.

\section{MODELLING OF BIDDING PROCEDURES}

In order to avoid mistakes and randomness in the contractor's bidding decisions it is suggested that these decisions have to be aided by a model procedure. The basis of such models is selecting the factors which influence the decision.

Research into the factors influencing bidding decisions was conducted in many countries, such as the USA (Ahmad, Minkarah 1988), Great Britain (Shash 1993), Syria (Wanous et al. 2000), Singapore (Chua, Li 2000) or Saudi Arabia (Bageis, Fortune 2009). Some was also done in Poland a number of times (Kosecki, Plebankiewicz 2000). The research method most frequently employed was the questionnaire since it allowed the researcher to reach a wide group of contractors easily and quickly. In 2004 in Great Britain a different type of research was performed, namely one based on the analysis of archival data which the authors received from those construction companies which were willing to participate in the research (Lowe, Parvar 2004). All these studies performed in vari- ous countries revealed that the recurring factors influencing the bid/no bid decisions included: the type of works, experience in the completion of similar projects, the need of work, current involvement in other projects, the owner, the size of the project, or the conditions specified in the contract. On the other hand, the factors which have the greatest influence on deciding about the height of the calculated mark-up introduced to the bidding offer are: the conditions payment for the works completed, the value of the construction project and experience in accomplishing similar ventures.

The selection of the above-mentioned factors was the basis for designing mathematical models concerning bid/no bid decisions. One of the first attempts to build a bid/no bid decision model was done by Ahmad (1990). Another solution of the problem were proposed by Wanous et al. (2000, 2003), Lin and Chen (2004), Egemen and Mohamed (2008).

First attempts at working out procedure that would be helpful in determining the most proper mark-up in a given situation were made in the fifties of the $20^{\text {th }}$ century. A pioneer work discussing the problem is the article written in 1956 by Friedman (1956). Subsequently there appeared numerous models which made use of different types of mathematical theories (Dikmen et al. 2007; Egemen, Mohamed 2008; Fayek 1998; Chua et al. 2001; Han, Diekmann 2001; Li, Love 1999).

In contractor evaluation numerous criteria are taken into account, which in turn are characterized by the right subcriteria. In many countries there were many studies concerning the criteria used by construction owners (Banaitienè, Banaitis 2006; Hatush, Skitmore 1997; Jennings, Holt 1998; Plebankiewicz 2010).

The basic criteria of contractor evaluation include financial standing, technical ability, management capability, health and safety, and reputation. In the literature there are several models which can be used in the process of selecting the right contractor (Brauers et al. 2008; Cheng, Li 2004; Elazouni 2006; El-Sayeg 2009; Jaselskis, Russell 1991; Lam et al. 2001, 2005; Mitkus, Trinkūnienè 2008).

\section{ASSUMPTIONS OF THE FUZZY SETS THEORY EMPLOYED IN THE BIDDING MODELS}

To build a model comprising all conditions for a bidding decisions made by both the contractor and construction owner is not an easy task. Evaluation of many factors and criteria is subjective and 
ambiguous in meaning, as exemplified by the following terms: "a long time of completion", "bad management", "good relations" or "contractor's reputation". It is also not an easy task to determine one common scale of evaluation for all the factors and criteria. Additionally, the necessity to include in the model evaluations of numerous decision-makers is also a problem. The objectives of the contractor or construction owner in a given project are also vital. The evaluation of the factors, criteria and evaluation of the contractor and construction owner objectives are difficult to quantify.

An attempt to present quantitatively the values which previously were considered to be immeasurable led in the sixties to the formulation of the fuzzy sets theory which began to be widely used in decision making procedures. According to this theory, linguistic variables can be converted into a fuzzy numbers. The fuzzy sets theory proves convenient for searching solutions to the problems generated by human subjectivity, such as making bidding decisions.

The advantages of employing the fuzzy sets theory to solve bidding problems encouraged many researchers to use them in their mathematical models aiding the decision making process of both contractors and construction owners. Such models were presented, for example, by RadziszewskaZielina (2011), Lin and Chen (2004) for bid/no bid decisions, Fayek (1998) for decisions about the height of the murk-up to be introduced into the bidding offer. Fuzzy sets were used to build a contractor selection model by Nguyen (1985), Singh and Tiong (2005), Plebankiewicz (2009).

The author of this article designed models employing fuzzy numbers and operations carried out with their use. In literature many definitions of fuzzy numbers can be found. One of the most accurate was provided by Goetschel and Voxman (1983) in:

The fuzzy number $A$ is a special type of a fuzzy set specified on a set of real numbers $(X=\mathrm{R})$ which, additionally, fulfils the following conditions:

- Is normal: a set is normal when there exists such an argument for which a function takes value 1 .

- Is convex: set A is convex when:

$$
\begin{aligned}
& \forall x, y \in X \quad \forall \lambda \in[0 ; 1], \\
& \mu_{A}(\lambda \cdot x+(1-\lambda) \cdot y) \geq \min \left(\mu_{A}(x), \mu_{A}(y)\right) .
\end{aligned}
$$

- Support of function $\mu_{A}(x)$ is an interval.

$-\mu_{A}(x)$ is a continuous interval function.

The model uses fuzzy numbers of trapezoid and triangular diagram. The trapezoid function is de-

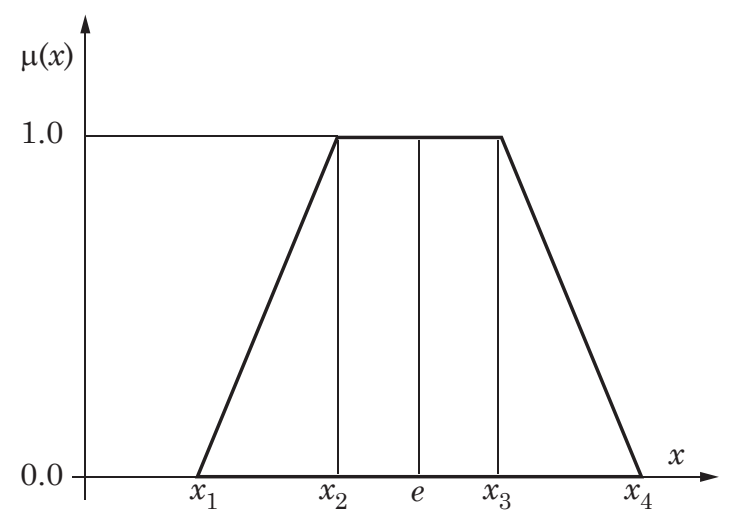

Fig. 1. Trapezoid membership function

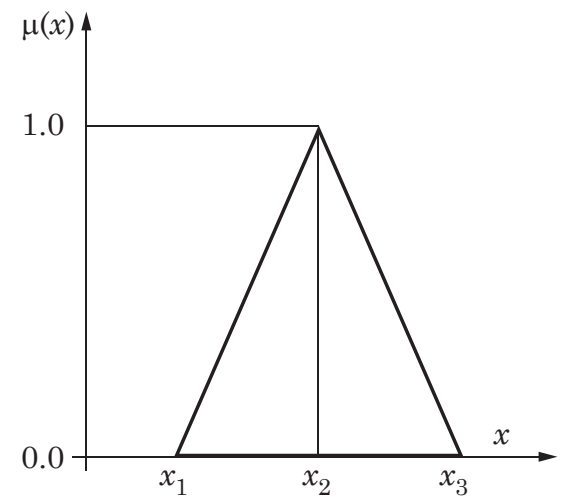

Fig. 2. Triangular membership function

picted in Figure 1 and the triangular one in Figure 2.

A description of a trapezoid membership function is also presented in literature by a table of values (formula 1 ):

$$
\mu_{A}(x)=\left\{\begin{array}{lc}
0, & x<x_{1} \\
\left(x-x_{1}\right) /\left(x_{2}-x_{1}\right), & x_{1}<x<x_{2} \\
1, & x_{2}<x<x_{3} \\
\left(x_{4}-x\right) /\left(x_{4}-x_{3}\right), & x_{3}<x<x_{4} \\
0, & x>x_{4}
\end{array}\right.
$$

The triangular membership function is also presented in literature in a table of values as in formula 2 .

$$
\mu_{A}(x)=\left\{\begin{array}{lc}
0, & x<x_{1} \\
\left(x-x_{1}\right) /\left(x_{2}-x_{1}\right), & x_{1}<x<x_{2} \\
\left(x_{3}-x\right) /\left(x_{3}-x_{2}\right), & x_{2}<x<x_{3} \\
0, & x>x_{3}
\end{array}\right.
$$

A fuzzy number can be interpreted as the four $\left\{x_{1}, x_{2}, x_{3}, x_{4}\right\}$. A fuzzy number with a trapezoid diagram can be then unambiguously specified as a problem of four ordered numbers, as in formula 3.

$$
X=\left\{x_{1}, x_{2}, x_{3}, x_{4}\right\} .
$$


A fuzzy number with a triangular diagram can be unambiguously specified as a problem of four ordered numbers, as in formula 4.

$$
X=\left\{x_{1}, x_{2}, x_{2}, x_{3}\right\} .
$$

On two fuzzy numbers $A=\left\{a_{1}, a_{2}, a_{3}, a_{4}\right\}, B=$ $\left\{b_{1}, b_{2}, b_{3}, b_{4}\right\}$ one can perform an operation of addition, subtraction, multiplication and division. They are illustrated by formulas 5, 6, 7, 8 (Kaufmann, Gupta 1991).

Addition:

$$
\begin{aligned}
& A \oplus B=\left(a_{1}, a_{2}, a_{3}, a_{4}\right) \oplus\left(b_{1}, b_{2}, b_{3}, b_{4}\right)= \\
& \left(a_{1}+b_{1}, a_{2}+b_{2}, a_{3}+b_{3}, a_{4}+b_{4}\right) .
\end{aligned}
$$

Subtraction:

$$
\begin{aligned}
& A(-) B=\left(a_{1}, a_{2}, a_{3}, a_{4}\right)(-)\left(b_{1}, b_{2}, b_{3}, b_{4}\right)= \\
& \left(a_{1}-b_{4}, a_{2}-b_{3}, a_{3}-b_{2}, a_{4}-b_{1}\right) .
\end{aligned}
$$

Multiplication:

$$
\begin{aligned}
& A \otimes B=\left(a_{1}, a_{2}, a_{3}, a_{4}\right) \otimes\left(b_{1}, b_{2}, b_{3}, b_{4}\right)= \\
& \left(a_{1} b_{1}, a_{2} b_{2}, a_{3} b_{3}, a_{4} b_{4}\right) .
\end{aligned}
$$

Division:

$$
\begin{aligned}
& A(\cdot) B=\left(a_{1}, a_{2}, a_{3}, a_{4}\right)(\cdot)\left(b_{1}, b_{2}, b_{3}, b_{4}\right)= \\
& \left(a_{1} / b_{4}, a_{2} / b_{3}, a_{3} / b_{2}, a_{4} / b_{1}\right) .
\end{aligned}
$$

Assuming that evaluations in the form of fuzzy numbers is done by a panel of decision makers according to specified criteria, it is necessary to establish a mean evaluation. This can be expressed by the following formula:

$$
\begin{aligned}
& A_{i j}^{k}=(1 / p) \otimes\left(a_{i 1}^{k} \oplus a_{i 2}^{k} \oplus \ldots \oplus a_{i p}^{k}\right) \\
& \forall j=1,2, \ldots, p,
\end{aligned}
$$

where: $k$ - the number of alternative evaluations $(k=1, \ldots, 4) ; i$ - evaluation of a factor $(i=1, \ldots m)$; $m$ - the number of factors; $j$ - decision maker $(j=$ $1, \ldots, p) ; p$ - the number of decision makers.

In order to obtain the crisp value of the fuzzy number various methods of defuzzification can be used. The simplest one in the case of the trapezoid membership function can be depicted as follows (Kaufmann, Gupta 1991):

$$
e=\left(x_{1}+x_{2}+x_{3}+x_{4}\right) / 4 .
$$

For triangular membership function:

$$
e=\left(x_{1}+2 x_{2}+x_{3}\right) / 4 \text {. }
$$

Apart from sets, another basic element used by the model is the fuzzy relation. Just as the fuzzy set is a generalization of a non-fuzzy set, so is the fuzzy relation a generalization of a non-fuzzy relation.

A two-argument fuzzy relation $\mathrm{R}$ between two (non-fuzzy) sets $\mathrm{X}=\{\mathrm{x}\}$ and $\mathrm{Y}=\{\mathrm{y}\}$ is defined as a fuzzy set specified by the Cartesian product $\mathrm{X} \times \mathrm{Y}$, i.e. $\mathrm{R} \subseteq \mathrm{X} \times \mathrm{Y}=\{(x, y): x \in \mathrm{X}, y \in \mathrm{Y}\}$ (Klir, Folger 1988). The relation is thus a set of pairs:

$$
\mathrm{R}=\left\{\left(\mu_{\mathrm{R}}(x, y),(x, y)\right)\right\}, \forall \mathrm{x} \in \mathrm{X}, \forall \mathrm{y} \in \mathrm{Y},
$$

where: $\mu_{\mathrm{R}}: \mathrm{X} \times \mathrm{Y} \rightarrow[0,1]$ is the membership function of the fuzzy relation $\mathrm{R}$ which assesses the gradual membership of its elements $\mu_{\mathrm{R}}(x, y) \in[0,1]$ of each pair $(x, y), x \in \mathrm{X}, y \in \mathrm{Y}$, which is the measure of the intensity of the fuzzy relation $\mathrm{R}$ between $x$ and $y$.

An $\mathrm{n}$-argument fuzzy relation between two (non-fuzzy) sets $\mathrm{X}_{1}=\left\{x_{1}\right\}, \mathrm{X}_{2}=\left\{x_{2}\right\}, \ldots \mathrm{X}_{\mathrm{n}}=\left\{x_{\mathrm{n}}\right\}$ is defined as a fuzzy set specified by the Cartesian product $\mathrm{X}_{1} \times \mathrm{X}_{2} \times \ldots \times \mathrm{X}_{\mathrm{n}}$, i.e. $\mathrm{R} \cong \mathrm{X}_{1} \times \mathrm{X}_{2} \times \ldots \times$ $\mathrm{X}_{\mathrm{n}}=\left\{\left(x_{1}, x_{2}, \ldots, x_{\mathrm{n}}\right): x_{1} \in \mathrm{X}_{1}, x_{2} \in \mathrm{X}_{2}, \ldots, x_{\mathrm{n}} \in \mathrm{X}_{\mathrm{n}}\right\}$. It is thus a set of pairs:

$$
\begin{aligned}
& \mathrm{R}=\left\{\left(\mu_{\mathrm{R}}\left(x_{1}, x_{2}, \ldots, x_{\mathrm{n}}\right),\left(x_{1}, x_{2}, \ldots, x_{\mathrm{n}}\right)\right)\right\}, \\
& \forall x_{1} \in \mathrm{X}_{1}, \forall x_{2} \in \mathrm{X}_{2}, \ldots, \forall x_{\mathrm{n}} \in \mathrm{X}_{\mathrm{n}},
\end{aligned}
$$

What is important here is the composition of two fuzzy relations. Specifying the composition of relations can be an example of how divergent fuzzy sets can be. There are various definitions of the composition of relations, where the most frequently defined one is the composition of the max-min relation.

Let us assume there are three non-fuzzy sets $\mathrm{X}=$ $\{x\}, \mathrm{Y}=\{y\}$ and $\mathrm{Z}=\{z\}$ with specified two fuzzy relations $\mathrm{R} \subseteq \mathrm{X} \times \mathrm{Y}$ and $\mathrm{G} \subseteq \mathrm{Y} \times \mathrm{Z}$ whose membership functions are $\mu_{\mathrm{R}}(x, y)$ and $\mu_{\mathrm{G}}(y, z)$. The description employs the definition given by Klir and Folger (1988):

A max-min composition of fuzzy relations $\mathrm{R} \subseteq$ $\mathrm{X} \times \mathrm{Y}$ and $\mathrm{G} \subseteq \mathrm{Y} \times \mathrm{Z}$ is a fuzzy relation $\mathrm{R}$ of $\mathrm{G} \subseteq \mathrm{X} \times$ $\mathrm{Z}$ of membership function:

$$
\mu_{\mathrm{R}_{\circ} \mathrm{G}}(x, z)=\max \min \left(\mu_{\mathrm{R}}(x, y), \mu_{\mathrm{G}}(y, z)\right) \text {. }
$$

The prequalification model presented here employs also a sum-min composition of fuzzy relations which can be defined as follows:

A sum-min composition of fuzzy relations $\mathrm{R} \subseteq \mathrm{X} \times \mathrm{Y}$ and $\mathrm{G} \subseteq \mathrm{Y} \times \mathrm{Z}$ is a fuzzy relation $\mathrm{R}$ of $\mathrm{G} \subseteq \mathrm{X} \times \mathrm{Z}$ of membership function:

$$
m_{R o G}(x, z)=\operatorname{sum} \min \left(\mu_{R}(x, y), m_{G}(y, z)\right) .
$$




\section{BIDDING MODELS}

\subsection{Bid/no bid}

The bid/ no bid model follows the following schema:

- In the first place the decision maker specifies the factors $c_{t}$ which he/she takes into consideration when making a decision.

- Decision makers $d_{p}$ establish the influence of a given factor on the decision to be made and the evaluation of a given factor for the particular construction project.

- For evaluation the decision makers use linguistic values:

Linguistic values \{Very Strong, Strong, Above Average, Average, Below Average, Weak, Very Weak\} relate to the evaluation of the influence of a given factor on the particular bidding decision to be made.

Linguistic values \{Very Advantageous, Advantageous, Above Average, Average, Below Average, Rather Disadvantageous, Very Disadvantageous\} relate to the evaluation of a given factor on the particular bidding decision to be made.

- The linguistic values are transformed into fuzzy forms.

Figure 3 shows a graphic representation of the fuzzy linguistic values. Using the formulas in (3) and (4) each linguistic value can be illustrated by means of ordered four numbers. The details are provided in Table 1.
For each factor the decision makers establish an evaluation of a factors' influence on the bidding decision to be made: $W_{i j}$ - evaluation of the influence of factor $i(i=1,2, \ldots, m)$ by decision maker $j$ $(j=1,2, \ldots, p): W_{i j}$ is specified by $\left(W_{i j}{ }^{1}, W_{i j}{ }^{2}, W_{i j}{ }^{3}\right.$, $\left.W_{i j}^{4}\right)$.

The final evaluation (i.e. the mean of all evaluations done by all decision makers, according to (9):

$$
\begin{aligned}
& W_{i}=\left(\left(W_{i 1}{ }^{1}+W_{i 2}{ }^{1}+\ldots W_{i p}{ }^{1}\right) / p,\left(W_{i 1}{ }^{2}+W_{i 2}{ }^{2}+\ldots\right.\right. \\
& \left.W_{i p}{ }^{2}\right) / p,\left(W_{i 1}{ }^{3}+W_{i 2}{ }^{3}+\ldots W_{i p}{ }^{3}\right) / p,\left(W_{i 1}^{4}+W_{i 2}{ }^{4}+\ldots\right. \\
& \left.\left.W_{i p}{ }^{4}\right) / p\right) .
\end{aligned}
$$

Introducing signatures:

$$
\begin{aligned}
& \left(W_{i 1}{ }^{1}+W_{i 2}{ }^{1}+\ldots W_{i p}{ }^{1}\right) / p=W_{i}^{1}, \\
& \left(W_{i 1}{ }^{2}+W_{i 2}{ }^{2}+\ldots W_{i p}{ }^{2}\right) / p=W_{i}{ }^{2}, \\
& \left(W_{i 1}{ }^{3}+W_{i 2}{ }^{3}+\ldots W_{i p}{ }^{3}\right) / p=W_{i}^{3}, \\
& \left(W_{i 1}{ }^{4}+W_{i 2}{ }^{4}+\ldots W_{i p}{ }^{4}\right) / p=W_{i}^{4}, \\
& W_{i}=\left(W_{i}^{1}, W_{i}^{2}, W_{i}^{3}, W_{i}^{4}\right) .
\end{aligned}
$$

The evaluation of a factor in a given project $\left(O_{i}\right)$ is done in the same manner.

Products of fuzzy numbers are created:

$$
\begin{aligned}
& W O_{i}=W_{i} \otimes O_{i}=\left(W_{i}^{1} O_{i}{ }^{1}, W_{i}^{2} O_{i}{ }^{2}, W_{i}^{3} O_{i}^{3},\right. \\
& \left.W_{i}^{4} O_{i}^{4}\right)=\left(C_{i}{ }^{1}, C_{i}^{2}, C_{i}^{3}, C_{i}^{4}\right) .
\end{aligned}
$$

The defuzzification value (the average value of factor evaluation) is specified.

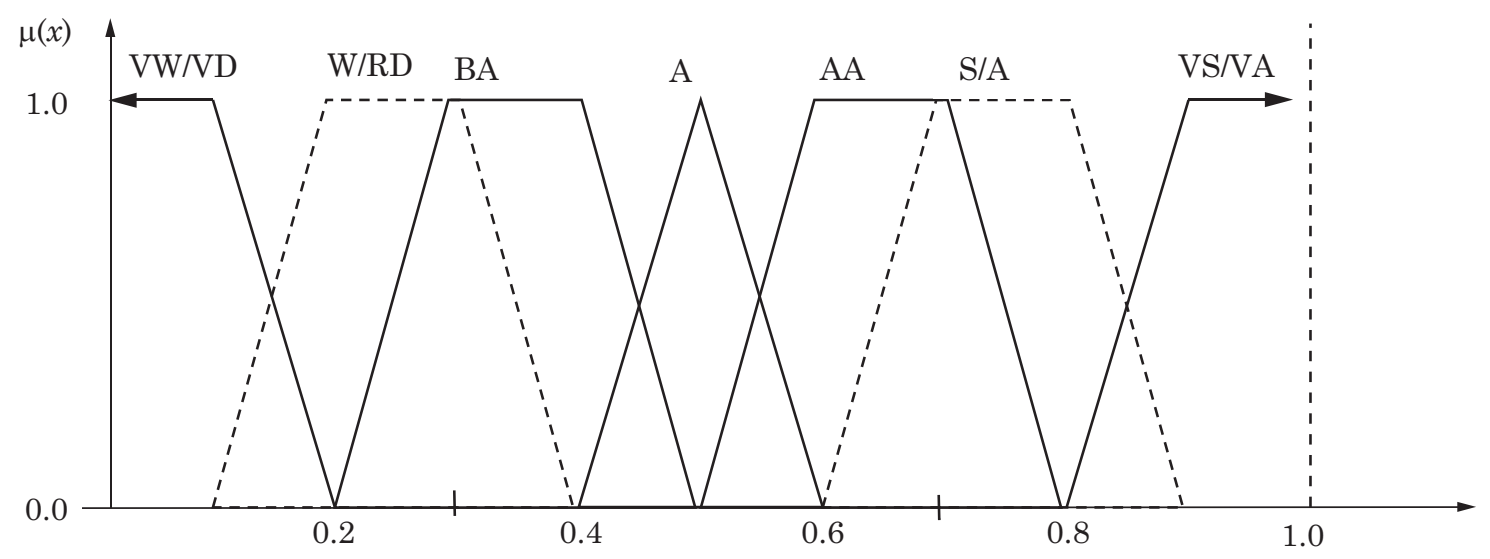

Fig. 3. A graphic representation of fuzzy linguistic values

Table 1. Interpretation of fuzzy linguistic values

\begin{tabular}{llc}
\hline $\begin{array}{l}\text { Linguistic values for the evaluation of } \\
\text { the factors' influence on a bidding decision }\end{array}$ & $\begin{array}{l}\text { Linguistic values for the evaluation of } \\
\text { a factor in a given project }\end{array}$ & $\begin{array}{l}\text { Fuzzy evaluation } \\
\text { (interpretation) }\end{array}$ \\
\hline VS - Very Strong & VA - Very Advantageous & $(0.8,0.9,1.0,1.0)$ \\
S - Strong, & A - Advantageous & $(0.6,0.7,0.8,0.9)$ \\
AA - Above Average & AA - Above Average & $(0.5,0.6,0.7,0.8)$ \\
A - Average & A - Average & $(0.4,0.5,0.5,0.6)$ \\
BA - Below Average & BA - Below Average & $(0.2,0.3,0.4,0.5)$ \\
W - Weak & RD - Rather Disadvantageous & $(0.1,0.2,0.3,0.4)$ \\
VW - Very Weak & VD - Very Disadvantageous & $(0.0,0.0,0.1,0.2)$ \\
\hline
\end{tabular}




$$
C_{i}=\left(C_{i}^{1}+C_{i}^{2}+C_{i}^{3}+C_{i}^{4}\right) / 4 \text {. }
$$

A $B / n o B$ index is specified as the average value of evaluation for all factors. The $B / n o B$ index is an index of recommendation for taking part in a given bid. The $B / n o B$ index can reach values from 0 to 0.9 . The closer to 1 the value is the more recommended taking part in the bidding under consideration is. The contractor may assume a threshold value of the index above which he/she will take part in the bid. It is suggested that the threshold value is $B / n o B>0.5$.

For evaluation one should take into account only these factors whose influence on the decision to be made fits in the very strong - average bracket. Using factors with lower evaluation can lower the final evaluation. More about the model you can find in Leśniak and Plebankiewicz (2013).

\subsection{Mark-up}

The model concerning mark-up uses the following procedure:

- The decision maker specifies the bracket of the calculated mark-up by providing its minimal $(x)$ and maximal $(y)$ value. The values are defined on the basis of an individual evaluation of a given bidding situation, the current market condition, etc.

The decision maker divides the calculated mark-up into 5 brackets. This particular division was chosen because it has been proved that distinguishing between more than 6 mark-up values is difficult (Saaty 1977; Fayek 1998). The values of the calculated mark-up $\mathrm{Z}_{\mathrm{k}}$ is set according to the following formula:

$$
Z_{k}=[x+(p-1) z] \% \text { for } p=1 \text { to } 6,
$$

where: $z=(y-x) / 5$.

- The decision maker identifies the objectives $o_{a}$ which are the contractor's goal in a given bidding. In general, the model accounts for the following objectives which the contractor wants to achieve in the bidding process: winning the bid $\left(o_{1}\right)$; maximizing mark-up $\left(o_{2}\right)$; testing the market $\left(o_{3}\right)$; minimizing the mark-up of competitors $\left(o_{4}\right)$; minimizing the predicted losses $\left(o_{5}\right)$. The construction, however, may take into consideration other objectives as well.

- The decision maker identifies factors $f_{n}$ which influence the decision about the height of the calculated mark-up.

- Decision makers $\left(d_{p}\right)$ evaluate the degree to which the construction owner aims at achieving a given objective, the degree of factors $f_{n}$ which influence the decision about the height of the calculated mark-up.

In the evaluation the decision makers used linguistic values:

Linguistic values - \{Very Important, Important, Above Average, Average, Below Average, Low Important, Very Low Important\}, refer to the evaluation of the degree of importance in aiming at reaching a given objective.

Linguistic values - \{Very Strong, Strong, Above Average, Average, Below Average, Weak, Very Weak $\}$ relate to the evaluation of factors $f_{n}$ which influence the decision about the height of the calculated mark-up.

- Linguistic values are converted into a fuzzy numbers (similarly as in case of bid/no bid decision).

- For each objective we determine fuzzy value of the degree to which a construction owner is striving in order to reach a given objective.

- $O_{j a}^{e}-j(j=1,2, \ldots, m)$ objective evaluation, by $a(a=1,2, \ldots, p)$ decision maker, for $e(e=$ $1,2,3,4)$ variant.

$$
O_{j a}^{\prime e}=\left[\begin{array}{cccc}
\left(O_{11}^{1}, O_{11}^{2}, O_{11}^{3}, O_{11}^{4}\right) & \left(O_{12}^{1}, O_{12}^{2}, O_{12}^{3}, O_{12}^{4}\right) & \ldots & \left(O_{1 p}^{1}, O_{1 p}^{2}, O_{1 p}^{3}, O_{1 p}^{4}\right) \\
\left(O_{21}^{1}, O_{21}^{2}, O_{21}^{3}, O_{21}^{4}\right) & \left(O_{22}^{1}, O_{22}^{2}, O_{22}^{3}, O_{22}^{4}\right) & \ldots & \left(O_{2 p}^{1}, O_{2 p}^{2}, O_{2 p}^{3}, O_{2 p}^{4}\right) \\
\cdot & & & \\
\left(O_{m 1}^{1}, O_{m 1}^{2}, O_{m 1}^{3}, O_{m 1}^{4}\right) & \left(O_{m 2}^{1}, O_{m 2}^{2}, O_{m 2}^{3}, O_{m 2}^{4}\right) & \ldots & \left(O_{m p}^{1}, O_{m p}^{2}, O_{m p}^{3}, O_{m p}^{4}\right)
\end{array}\right] .
$$

The average score of decision makers:

$$
O_{j a}^{\prime \prime e}=\left[\begin{array}{cccc}
\left(O_{11}^{1}+O_{12}^{1}+\ldots+O_{1 p}^{1}\right) / p & \left(O_{11}^{2}+O_{12}^{2}+\ldots+O_{1 p}^{2}\right) / p & \left(O_{11}^{3}+O_{12}^{3}+\ldots+O_{1 p}^{3}\right) / p & \left(O_{11}^{4}+O_{12}^{4}+\ldots+O_{1 p}^{4}\right) / p \\
\left(O_{21}^{1}+O_{22}^{1}+\ldots+O_{2 p}^{1}\right) / p & \left(O_{21}^{2}+O_{22}^{2}+\ldots+O_{2 p}^{2}\right) / p & \left(O_{21}^{3}+O_{22}^{3}+\ldots+O_{2 p}^{3}\right) / p & \left(O_{21}^{4}+O_{22}^{4}+\ldots+O_{2 p}^{4}\right) / p \\
\cdot & & & \\
\left(O_{m 1}^{1}+O_{m 2}^{1}+\ldots+O_{m p}^{1} / p\right. & \left(O_{m 1}^{2}+O_{m 2}^{2}+\ldots+O_{m p}^{2}\right) / p & \left(O_{m 1}^{3}+O_{m 2}^{3}+\ldots+O_{m p}^{3}\right) / p & \left(O_{m 1}^{4}+O_{m 2}^{4}+\ldots+O_{m p}^{4}\right) / p
\end{array}\right] .
$$


Introducing denotations:

$$
\begin{aligned}
& \left(O_{11}^{1}+O_{12}^{1}+\ldots+O_{1 p}^{1}\right) / p=O_{11}, \\
& \left(O_{11}^{2}+O_{12}^{2}+\ldots+O_{1 p}^{2}\right) / p=O_{12}, \\
& \left(O_{11}^{3}+O_{12}^{3}+\ldots+O_{1 p}^{3}\right) / p=O_{13}, \\
& \left(O_{11}^{4}+O_{12}^{4}+\ldots+O_{1 p}^{4}\right) / p=O_{14}, \\
& \left(O_{21}^{1}+O_{22}^{1}+\ldots+O_{2 p}^{1}\right) / p=O_{21}, \\
& \left.O_{21}^{2}+O_{22}^{2}+\ldots+O_{2 p}^{2}\right) / p=O_{22}, \\
& \ldots \\
& \left(O_{m 1}^{3}+O_{m 2}^{3}+\ldots+O_{m p}^{3}\right) / p=O_{m 3}, \\
& \left(O_{m 1}^{4}+O_{m 2}^{4}+\ldots+O_{m p}^{4}\right) / p=O_{m 4} .
\end{aligned}
$$

Objective evaluation matrix is obtained as follows:

$$
O_{j a}=\left[\begin{array}{cccc}
O_{11} & O_{12} & O_{13} & O_{14} \\
O_{21} & O_{22} & O_{23} & O_{24} \\
\cdot & & & \\
O_{m 1} & O_{m 2} & O_{m 3} & O_{m 4}
\end{array}\right] .
$$

- The crisp score (defuzzified value) - the average degree to which a construction owner is striving in order to reach a given objective - is obtained as follows (Kaufmann, Gupta 1991):

$$
O_{j}=\left(O_{j 1}+O_{j 2}+O_{j 3}+O_{j 4}\right) / 4
$$

Next, similarly as in the case of the degree to which a construction owner is striving in order to reach a given objective, the degree to which factors $f_{n}$ which influence the decision about the height of the calculated mark-up $\left(F_{n}\right)$ are considered.

- The decision maker identifies the degree $\left(I_{j n}\right)$ to which factor $F_{n}$ influences objective $O_{j}$, and the value of the calculated mark-up which is the best for the given pair objective - factor.

- The decision maker calculates the elements $S(O, F)$ using the following formula:

$$
S\left(O_{j}, F_{n}\right)=W_{j} \cdot A_{n} \cdot I_{j n} \text {. }
$$

$S(O, F)$ is a fuzzy relation which specifies the relationship between factor $F$ and objective $O$.

- The decision maker assigns elements $R(F, Z)$, where $R(F, Z)$ is a fuzzy relation specifying the relationship between factor $F$ and markup $Z$.

- The decision maker assigns elements $Q(O, Z)$ which are a composition of two fuzzy relations $S(O, F)$ and $R(F, Z)$, and which specify the dependency between objective $O$ and calculated mark-up $Z$ through their relationship with factor $F$.
The composition of the relations is assigned according to the max-min and sum-min rule.

- The composition of the max-min relation for data $O_{j}$ i $Z_{k}$ is specified by:

$$
\begin{aligned}
& S \text { o } R\left(O_{j}, Z_{k}\right)=\max \min \left[S\left(O_{j}, F_{n}\right), R\left(F_{n}, Z_{k}\right)\right] \\
& \text { for every } F_{n} .
\end{aligned}
$$

For any value of the calculated mark-up $Z_{k}$ the general force with which it is recommended is calculated according to the following formula:

$$
Q\left(O, Z_{k}\right)=\left[S Q\left(O_{j}, Z_{k}\right)\right] / S W_{j} \text { for } j=1 \text { to } \mathrm{m} \text {. }
$$

- The composition of the sum-min relation for data $O_{j}$ and $Z_{k}$ is specified by:

$$
\begin{aligned}
& S \text { o } R\left(O_{j}, Z_{k}\right)=\operatorname{sum} \min \left[S\left(O_{j}, F_{n}\right), R\left(F_{n}, Z_{k}\right)\right] \\
& \text { for every } F_{n} .
\end{aligned}
$$

For any value of the calculated mark-up $Z_{k}$ the general force with which it is recommended is calculated according to the following formula (21).

In the next stage the force with which the given calculated mark-up in a bid is recommended to be used is corrected because of the introduction of two additional elements:

1. The importance which the orderer attaches to the price provided in the bid;

2 . The index of the percentage of those bidding settlements in which the offer with the lowest bid price won.

Theoretically, it can be assumed that if the orderer, while evaluating a bid, specifies importance of $0 \%$ for the price criterion, you can introduce a maximal value of the calculated mark-up, i.e. $Z_{6}$ to the bidding offer (the price for the orderer is immaterial, so the highest value can be given freely). On the other hand, if the orderer gives the price criterion the highest value, i.e. $100 \%$, the lowest value of the calculated mark-up, i.e. $Z_{1}$, should best be provided (if price is of such considerable importance, your chances will be the greatest when you give the lowest value of the calculated mark-up). The intermediate values of price importance correspond to the relevant values of the calculated mark-up. These dependencies are illustrated by Figure 4.

Assuming that $B_{x}$ is the importance which the orderer attaches to the price criterion in a given bid, the dependence between $B_{x}$ and the value of calcualted mark-up $Z_{y}$ can be described as follows:

$$
Z_{y}=\left(Z_{1}-Z_{6}\right) B_{x}+Z_{6} .
$$




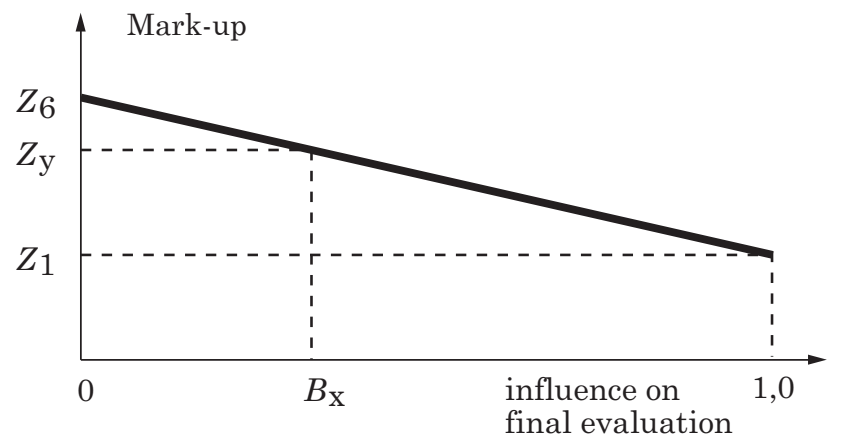

Fig. 4. Graphical interpretation of $B_{x}$ coefficient

The value of calculated mark-up $Z_{y}$ obtained in this way is the most advantageous for the contractor from the point of view of the importance which the orderer attaches to the price criterion when evaluating bids. To this value coefficient 1.0 is ascribed and to the other values of calculated mark-up - coefficients reduced by 0.2 respectively. In this way you receive a corrected degree of recommendation as to the introduction of calculated mark-up $Z_{k}$, specified as $Q_{K}\left(Z_{k}\right)$, to the bid.

The decision maker specifies the index of the percentage of those bidding processes in which the winning bid offered the minimal price, i.e. $C_{x}$. This can be either the last year's index or the average one from a couple of previous years. For the lowest price (the lowest calculated profit, $Z_{1}$ ) coefficient $C_{x}$ is assumed. For the highest price (the highest calculated mark-up, $Z_{6}$ ) coefficient 1.00 is adopted, and for the other values of calculated mark-up coefficients changing proportionally.

A general description is as follows:

Let $Q_{o}\left(Z_{k}\right)$ indicate the final degree of recommendation of introducing calculated mark-up $Z_{k}$ to the bid. Then:

$$
Q_{O}\left(Z_{k}\right)=\left\{Q_{K}\left(Z_{k}\right) \cdot\left[C_{x}+g \cdot(p-1)\right]\right\},
$$

where $g=\frac{1-C_{x}}{5}$. More about the model you can find in Plebankiewicz and Leśniak (2013).

\subsection{Prequalification}

A prequalification model employing fuzzy sets number created by the author was described in detail in, for instance, Plebankiewicz (2009).

The model uses the following algorithm.

- In the first stage the construction owner has to define the objectives $\left(c_{m}\right)$ he/she wants to achieve in the project. In the model three objectives were taken into consideration: time $\left(c_{2}\right)$, cost $\left(c_{2}\right)$, and quality $\left(c_{3}\right)$. The construction owner, however, may take into consideration other objectives as well.
- We determine $k_{n}$ criteria having influence on the decision about a contractor being qualified.

- Decision makers $\left(d_{p}\right)$ evaluate the degree to which the construction owner aims at achieving a given objective, the degree of criteria importance for the construction owner and the degree of satisfying criteria by particular contractors.

- In the evaluation the decision makers used linguistic variables:

Linguistic values - \{Very Important, Important, Above Average, Average, Below Average, Low Important, Very Low Important\}, refer to the evaluation of the degree of importance in aiming at reaching a given objective and to the evaluation of a given criterion.

Linguistic values - \{Very Good, Good, Above Average, Average, Below Average, Poor, Very Poor\}, refer to the evaluation of the degree of contractor's satisfying the criterion.

- Linguistic values are converted into a fuzzy numbers (similarly as in case of bid/no bid decision).

- For each objective we determine a fuzzy value of the degree to which a construction owner is striving in order to reach a given objective $C_{a}$.

Next, similarly as in the case of the degree to which a construction owner is striving in order to reach a given objective, the degree of criterion importance and degree of satisfying criteria by particular contractors is established $\left(K_{b}\right)$.

- For each contractor, we determine the fuzzy value of criteria satisfying particular contractors:

$W_{c j b}^{e}-c(c=1,2, \ldots, t)$ contractor evaluation, by $j$ decision maker, for $e$ variant, according to $b$ criterion; $t$ - number of contractors.

Contractor evaluation matrix: $W_{c j b}$.

- The crisp score (defuzzified value) - the average degree of satisfying criteria by particular contractors: $W_{c b}$.

- The elements of the $R(c, k)$ relation are calculated, where $R(c, k)$ is a fuzzy binary relation approximates the relationship between the objective set and criteria set:

$R\left(c_{a}, k_{b}\right)=C_{a} \times K_{b} \times I_{a b}$.

- The elements of the $R(k, w)$ relation are calculated, where $R(k, w)$ is a fuzzy binary relation. Each element of $R(k, w)$ represents the degree of satisfying criteria by particular contractors.

- The elements of the $Q(c, w)$ relation are calculated, where $Q(c, w)$ is a fuzzy composition 
operation, performed on the two fuzzy binary relations $R(c, k)$ and $R(k, w)$. The elements of the $Q(c, w)$ relation determine the relationship between objective $c$ and contractor $w$ through their respective relationships to criterion $k$.

We use maximum-minimum (max-min) and cumulative-minimum (cum-min) composition operation.

- The max-min operation is defined, for a given $c_{a}$ and $w_{c}$, by:

$$
\begin{aligned}
& Q(c, w)=S \cdot R\left(c_{a}, w_{c}\right)= \\
& \max \min \left[R\left(c_{a}, k_{b}\right), R\left(k_{b}, w_{c}\right)\right] \text { for all } k_{b} .
\end{aligned}
$$

Contractor evaluations are obtained as follows:

$$
O_{i}=\left[\sum Q\left(c_{a}, w_{c}\right)\right] / \sum c_{a} \text { for } a=1 \text { to } m \text {. }
$$

- The cum-min operation is defined, for a given $c_{a}$ and $w_{c}$, by:

$$
\begin{aligned}
& Q(c, w)=S \cdot R\left(c_{a}, w_{c}\right)= \\
& \text { sum } \min \left[R\left(c_{a}, k_{b}\right), R\left(k_{b}, w_{c}\right)\right] \text { for all } k_{b}
\end{aligned}
$$

Contractor evaluations are obtained using (28). An example of how the model works is presented, for instance, in Plebankiewicz (2009).

\section{CONCLUSIONS}

Bidding procedures involve not only contractors but also construction owner making a number of vital decisions. What is essential for the orderer of construction works, including a real estate manager, is the choice of an appropriate contractor. This issue should become an element of the real estate management strategy and lead to a rational financing of the works necessary to maintain the good condition of the building. The contractor, on the other hand, has to make a number of decisions concerning their participation in the bid. To make the right decisions and to prepare the appropriate strategy, both the orderer and the contractor need the applicable information.

The fuzzy sets theory seems the most relevant for solving the problems generated by the specific character of the decisions made here. The theory allows to handle precisely the imprecise values and the decision makers can perform evaluations in the form of linguistic variables.

The article described the models concerning $\mathrm{bid} / \mathrm{no}$ bid decisions and the specification of the mark-up introduced into the offer, as well as the owners' evaluations of contractors wishing to take part in the bid.
The proposed prequalification model lets the owner evaluate contractors willing to participate in the bid and rank them on the basis of the evaluation. As a consequence, the bid is joined exclusively by those contractors whose knowledge, experience and resources allow to fulfill the orderer's requirements most closely. Moreover, the model lets the contractor, who has a limited number of bids s/ he can participate in, prepare the most advantageous offer. Another model allows the contractor to establish the profit level to be introduced to the quotation, which makes it possible to propose a bid being both competitive and cost-effective. All the models are based on the same simple mathematical apparatus employing fuzzy sets. Yet applying them in practice requires further investigation and testing. It is essential that they are used in the form of computer programs. Such programs are currently at the stage of testing.

\section{REFERENCES}

Ahmad, I. 1990. Decision-support system for modeling bid/no-bid decision problem, Journal of Construction Engineering and Management 116(4): 595-608. http://dx.doi.org/10.1061/(ASCE)07339364(1990)116:4(595)

Ahmad, I.; Minkarah, I. 1988. Questionnaire survey on bidding in construction, Journal of Management in Engineering 4(3): 229-243. http://dx.doi.org/10.1061/ (ASCE)9742-597X(1988)4:3(229)

Bageis, A. S.; Fortune, C. 2009. Factors affecting the bid/no bid decision in the Saudi Arabian construction contractors, Construction Management and Economics 27(1): 53-71. http://dx.doi. org/10.1080/01446190802596220

Banaitienè, N.; Banaitis, A. 2006. Analysis of criteria for contractors' qualification evaluation, Technological and Economic Development of Economy 12(4): 276-282. http://dx.doi.org/10.1080/13928619.2006.9 637754

Brauers, W. K. M.; Zavadskas, E. K.; Turskis, Z.; Vilutienè, T. 2008. Multi-objective contractor's ranking by applying the MOORA method, Journal of Business Economics and Management 9(4): 245-255. http://dx.doi.org/10.3846/1611-1699.2008.9.245-255

Cheng, E.; Li, H. 2004. Contractor selection using the analytic network process, Construction Management and Economics 22(10): 1021-1032. http://dx.doi. org/10.1080/0144619042000202852

Chua, D. K. H.; Li, D. 2000. Key factors in bid reasoning model, Journal of Construction Engineering and Management 126(5): 349-357. http://dx.doi. org/10.1061/(ASCE)0733-9364(2000)126:5(349)

Chua, D. K. H.; Li, D.; Chan, W. T. 2001. Case-based reasoning approach in bid decision making, Journal of Construction Engineering and Management 127(1): 35-45. http://dx.doi.org/10.1061/(ASCE)07339364(2001)127:1(35) 
Dikmen, I.; Birgonul, M. T.; Gur, A. K. 2007. A casebased decision support tool for bid mark-up estimation of international construction projects, Automation in Construction 17(1): 30-44. http://dx.doi. org/10.1016/j.autcon.2007.02.009

Egemen, M.; Mohamed, A. 2008. SCBMD: a knowledgebased system software for strategically correct bid/no bid and mark-up size decisions, Automation in Construction 17(7): 864-872. http://dx.doi.org/10.1016/j. autcon.2008.02.013

Elazouni, A. M. 2006. Classifying construction contractors using unsupervised-learning neural networks, Journal of Construction Engineering and Management 132(12): 1242-1253. http://dx.doi.org/10.1061/ (ASCE)0733-9364(2006)132:12(1242)

El-Sayeg, S. M. 2009. Multi-criteria decision support model for selecting the appropriate construction management at risk firm, Construction Management and Economics 27(4): 385-398. http://dx.doi. org/10.1080/01446190902759009

Fayek, A. 1998. Competitive bidding strategy model and software system for bid preparation, Journal of Construction Engineering and Management 124(1): 1-10. http://dx.doi.org/10.1061/(ASCE)07339364(1998)124:1(1)

Friedman, L. 1956. A competitive-bidding strategy, $O p$ erations Research 4(1): 104-112.

Goetschel, R.; Voxman, W. 1983. Topological properties of fuzzy numbers, Fuzzy Sets and Systems 10(1-3): 8799. http://dx.doi.org/10.1016/S0165-0114(83)80107-9

Han, S. H.; Diekmann, J. E. 2001. Making a risk-based bid decision for overseas construction projects, Construction Management and Economics 19(8): 765776. http://dx.doi.org/10.1080/01446190110072860

Hatush, Z.; Skitmore, M. 1997. Evaluating contractor prequalification data: selection criteria and project success factors, Construction Management and Economics 15(2): 129-147. http://dx.doi. org/10.1080/01446199700000002

Jaselskis, E. J.; Russell, J. S. 1991. An efficiently structured approach for selection of most promising construction contractors, Project Management Journal 12(4): 31-39.

Jennings, P.; Holt, G. D. 1998. Prequalification and multi-criteria selection: a measure of contractors' opinions, Construction Management and Economics 16(6): 651-660. http://dx.doi.org/10.1080/014461998371944

Kaufmann, A.; Gupta, M. M. 1991. Introduction to fuzzy arithmetic theory and application. New York: Van Nostrand Reinhold.

Klir, G. J.; Folger, T. A. 1988. Fuzzy sets, uncertainty and information. Englewood Cliffs, N.J.: PrenticeHall.

Kosecki, A.; Plebankiewicz, E. 2000. Factors influencing bid decisions of Polish construction firms, in Conference on Processes of construction, Gliwice-Kokotek, Poland, 93-100.

Lam, K. C.; Hu, T.; Ng, S. T. 2005. Using the principal component analysis method as a tool in contractor pre-qualification, Construction Management and Economics 23(7): 673-684. http://dx.doi. org/10.1080/01446190500041263

Lam, K. C.; Hu, T.; Ng, S. T.; Skitmore, M.; Cheung, S. O. 2001. A fuzzy neural network approach for contractor prequalification, Construction Management and Economics 19(2): 175-188. http://dx.doi. org/10.1080/01446190150505108
Leśniak, A.; Plebankiewicz, E. 2013. The modeling of the decision-making process concerning participation in the construction bidding, Journal of Management in Engineering. http://dx.doi.org/10.1061/(ASCE) ME.1943-5479.0000237

Li, H.; Love, P. E. D. 1999. Combining rule-based expert systems and artificial neural networks for mark-up estimation, Construction Management and Economics 17(2): 169-176. http://dx.doi. org/10.1080/014461999371664

Lin, C. T.; Chen, Y. T. 2004. Bid/no-bid decision-making - a fuzzy linguistic approach, International Journal of Project Management 22(7): 585-593. http:// dx.doi.org/10.1016/j.ijproman.2004.01.005

Lowe, D. J.; Parvar, J. 2004. A logistic regression approach to modelling the contractor's decision to bid, Construction Management and Economics 22(6): 643-653. http://dx.doi.org/10.1080/01446190310001 649056

Mitkus, S.; Trinkūnienè, E. 2008. Reasoned decisions in construction contracts evaluation, Technological and Economic Development of Economy 14(3): 402-416. http://dx.doi.org/10.3846/1392-8619.2008.14.402-416

Nguyen, V. U. 1985. Tender evaluation by fuzzy sets, Journal of Construction Engineering and Management 111(3): 231-243. http://dx.doi.org/10.1061/ (ASCE)0733-9364(1985)111:3(231)

Plebankiewicz, E. 2009. Contractor prequalification model using fuzzy sets, Journal of Civil Engineering and Management 15(4): 377-385. http://dx.doi. org/10.3846/1392-3730.2009.15.377-385

Plebankiewicz, E. 2010. Construction contractor prequalification from Polish clients' perspective, Journal of Civil Engineering and Management 16(1): 57-64. http://dx.doi.org/10.3846/jcem.2010.05

Plebankiewicz, E.; Leśniak, A. 2011. Ocena i wybór wykonawcy robót budowlanych przez inwestorów publicznych [Evaluation and choice of building contractors by public investors], Zeszyty Naukowe Politechniki Rzeszowskiej, 265-272.

Plebankiewicz, E.; Leśniak, A. 2013. Overhead costs and profit calculation by Polish contractors, Technological and Economic Development of Economy 19(1): $141-161$

Radziszewska-Zielina, E. 2011. Fuzzy control of the partnering relations of a construction enterprise, Journal of Civil Engineering and Management 17(1): 5-15. http://dx.doi.org/10.3846/13923730.2011.554172

Saaty, T. L. 1977. A scaling method for priorities in hierarchical structures, Journal of Mathematical Psychology 15(3): 234-281. http://dx.doi.org/10.1016/00222496(77)90033-5

Shash, A. A. 1993. Factors considered in tendering decisions by top UK contractors, Construction Management and Economics 11(2): 111-118. http://dx.doi. org/10.1080/01446199300000004

Singh, D.; Tiong, R. L. K. 2005. A fuzzy decision framework for contractor selection, Journal of Construction Engineering and Management 131(1): 62-70. http:// dx.doi.org/10.1061/(ASCE)0733-9364(2005)131:1(62)

Wanous, M.; Boussabaine, A. H.; Lewis, J. 2000. To bid or not to bid: a parametric solution, Construction Management and Economics 18(4): 457-466. http:// dx.doi.org/10.1080/01446190050024879

Wanous, M.; Boussabaine, A. H.; Lewis, J. 2003. A neural network bid/no bid model: the case for contractors in Syria, Construction Management and Economics 21(7): 737-744. http://dx.doi. org/10.1080/0144619032000093323 